\title{
Observation and Quantification of Crack Nucleation in Ferrite- Cementite Steel
}

\author{
Kazuki SHIBANUMA, ${ }^{1 * *}$ Shuji AIHARA ${ }^{1)}$ and Shigeru OHTSUKA ${ }^{21}$ \\ 1) Department of Systems Innovation, The University of Tokyo, 7-3-1, Hongo, Bunkyo-ku Tokyo, Japan. \\ 2) Institute of Engineering Innovation, The University of Tokyo, 7-3-1, Hongo, Bunkyo-ku Tokyo, Japan.
}

(Received on December 4, 2013; accepted on March 10, 2014; originally published in Tetsu-to-Hagané, Vol. 99, 2013, No. 9, pp. 582-591)

\begin{abstract}
It is known that a cracking of brittle phase such as cementite works as a trigger of cleavage fracture initiation. This study shows a microscopic observation of cracked cementite and its quantitation of the cracking nucleation in ferrite-cementite steels. Seven steels with various sizes of microstructures are produced by laboratory scale vacuum melting and rolling. The cementite particle thickness was measured by a SEM observation and an image analysis. Tensile tests using circumferential notched round bar specimens were conducted. A trace analysis of cleavage surface of cementite using the EBSD analysis indicated a possibility that the cleavage surface coincides with (010) plane. Distributions of cementite particle crack lengths were measured for various strain and stress conditions. In order to understand a microscopic internal stress of cementite particle, a finite element analysis was carried out. An estimation formula of internal stress of the cementite particle from macroscopic stress and strain was developed based on the numerical results. A nucleation of cementite cracking should be quantitated based on a stochastic framework because of its uncertainties such as distribution, shape, orientation and so on. The measured distributions of cementite particle thickness and crack length were approximated by introducing a distribution function considering upper limit. Probability of nucleation of cementite cracking was formulated as a function of cementite particle thickness and macroscopic stress and strain, based on the approximated distribution function and the estimation formula of internal stress of the cementite particle.
\end{abstract}

KEY WORDS: cementite particle; crack; fracture nucleation; fracture toughness; ferrite-cementite steel; EBSD analysis.

\section{Introduction}

A brittle fracture in a steel structure is caused by a cleave fracture of microstructures and shows rapid crack propagation with little plastic deformation. The brittle fracture must be prevented because it occurs with little warning and may cause a great damage.

It is widely known that a fracture toughness as a resistance of cleavage fracture initiation depends on the grain size. ${ }^{1)}$ It is also known that a brittle phase such as cementite works as a trigger of cleavage fracture, and thus the fracture toughness depends on the size of brittle phase. ${ }^{2)}$ According to these facts, it is important to clarify the relationship between microstructures and fracture toughness for material developments.

In the past researches on the estimation of fracture toughness considering the influence of microstructures, Almond et al. $^{3)}$ and Petch ${ }^{4)}$ proposed the estimation models considering the sizes of ferrite grain and cementite particle. Their researches were based on an assumption of a non-equilibrium behavior of crack in a cementite particle considering the dis-

* Corresponding author: E-mail: shibanuma@struct.t.u-tokyo.ac.jp DOI: http://dx.doi.org/10.2355/isijinternational.54.1719 location theory. However, their models are too simple to achieve a sufficient accuracy for actual use. One of the major reasons is that the fracture nucleation by cementite cracking was not considered.

Kaechele \& Tetelman, ${ }^{5)}$ Lindley et al. ${ }^{6)}$ and Gurland ${ }^{7)}$ investigated the cementite cracking by experimental studies. Their achievements showed that a probability of cementite cracking depends on plastic strain and yield stress. However, the influence of the distribution of cementite particle size and the microscopic behaviors of microstructures were not sufficiently considered. Therefore, the systematic experiments and the effective analyses are required.

The cleavage fracture of steel is generally interpreted by the weakest link mechanism which is completely different from yielding and work hardening. Thus, the scatter in the fracture toughness is its intrinsic feature. Considering this feature, Beremin proposed a model to evaluate a possibility of fracture using Weibull distribution function. ${ }^{8)}$ The effectiveness of this model has been widely accepted, because it enables quantitative evaluation of the scatter and the size effect on fracture toughness which were limited to be empirically treated in the past. ${ }^{9,10)}$ The original model was based on the assumption that there is the distribution of small defects in the microstructures in advance. Thus, some mod- 
ifications were then proposed by introducing an effect of strain considering nucleation of the small defects. ${ }^{11-13)}$ However, the relationship between microstructure and fracture toughness has been never clarified by the above models.

On the other hand, the authors recently proposed a numerical model to predict a fracture toughness of ferrite-cementite steel. ${ }^{14)}$ This model requires only the stress-strain curve, distributions of ferrite grain size and cementite particle thickness, but not any fitting parameters. It was developed considering three stages on the microscopic process of cleavage fracture initiation: (I) a formation of fracture nucleation by cementite cracking; (II) a propagation of the cementite crack into a ferrite matrix and formation of a cleavage crack; and (III) a propagation of the cleavage crack across ferrite grain boundary. As a fracture condition of the stage (I), a probability of cementite cracking was formulated based on experimental results using steels with various distributions of cementite particle thickness. However, in the proposed model, the microscopic mechanical foundation was not considered, and the formulation was organized using the representative values of cementite particle thickness.

According to the above background, the present paper describes a detailed observation and its quantification based on experiments and finite element analyses. The proposed quantification can directly apply to the prediction model of cleavage fracture toughness. ${ }^{14)}$

\section{Test Steels ${ }^{14)}$}

\subsection{Preparation of the Test Steels}

In the author's previous study, the test steels with various sizes of ferrite grains and cementite particles were produced by the combination of laboratory vacuum melting and rolling. ${ }^{14)}$ We employed the same steels in the present study.

The steels have two types of chemical compositions as shown in Table 1. It can be regarded that their compositions are the same except carbon concentration.

After pre-rolling of ingot, the steel plates with $25 \mathrm{~mm}$ in

Table 1. Chemical compositions of tested steels [mass\%].

\begin{tabular}{cccccccc}
\hline Symbol & $\mathrm{C}$ & $\mathrm{Si}$ & $\mathrm{Mn}$ & $\mathrm{P}$ & $\mathrm{S}$ & $\mathrm{Al}$ & $\mathrm{N}$ \\
\hline 10 & 0.10 & 0.06 & 0.49 & $<0.002$ & 0.0005 & 0.010 & 0.0011 \\
5 & 0.05 & 0.05 & 0.48 & $<0.002$ & 0.0003 & 0.010 & 0.0014 \\
\hline
\end{tabular}

thickness were produced by hot-rolling or combination of controlled rolling and controlled cooling. A plate produced by hot-rolling is called 'steel 10a' and the other produced by combination of controlled rolling and controlled cooling are called 'steel 10b' or 'steel 5', as shown in Table 2. Ferritepearlite structures with various ferrite grain sizes were made by normalizing as shown in Table 3. Finally, the cementite was coarsened to various particle sizes by annealing, and seven types of steels were produced, as shown in Table 4.

\subsection{Measurements of Cementite Particle Thickness}

Samples were extracted from the center of thickness of the respective steel plates. The SEM observation surfaces were polished and etched by nital. The cementite particle thickness was then measured as a minor axis of approximated ellipse of digitized images. ${ }^{15)}$ SEM images of 8-22 were measured for each steel. The shape of each particle is approximated. Figure 1 shows an example of the SEM images and the results of approximation. It was not distinguished whether the particles are located at the interior of the grains or at grain boundaries.

The SEM observation was selectively conducted for the

Table 3. Heat treatment conditions.

\begin{tabular}{|c|c|c|c|c|c|c|c|}
\hline \multirow{2}{*}{\multicolumn{2}{|c|}{ Symbol }} & \multicolumn{3}{|c|}{ Normalizing } & \multicolumn{3}{|c|}{ Annealing } \\
\hline & & Heating & Holding & Cooling & Heating & Holding & Cooling \\
\hline $10 \mathrm{LL}$ & \multirow{4}{*}{$10 \mathrm{a}$} & \multirow{3}{*}{$950^{\circ} \mathrm{C}$} & \multirow{3}{*}{$1 \mathrm{~h}$} & \multirow{4}{*}{ Air } & $700^{\circ} \mathrm{C}$ & $4 \mathrm{~h}$ & \multirow{4}{*}{ Air } \\
\hline $10 \mathrm{LM}$ & & & & & $600^{\circ} \mathrm{C}$ & $1 \mathrm{~h}$ & \\
\hline $10 \mathrm{LS}$ & & & & & $500^{\circ} \mathrm{C}$ & $0.5 \mathrm{~h}$ & \\
\hline $10 \mathrm{MM}$ & & $870^{\circ} \mathrm{C}$ & $0.5 \mathrm{~h}$ & & $600^{\circ} \mathrm{C}$ & $1 \mathrm{~h}$ & \\
\hline $10 \mathrm{SS}$ & $10 \mathrm{~b}$ & \multirow{3}{*}{\multicolumn{3}{|c|}{ As rolled and cooled }} & \multicolumn{3}{|c|}{ None } \\
\hline $5 \mathrm{SL}$ & \multirow{2}{*}{$5 \mathrm{a}$} & & & & $700^{\circ} \mathrm{C}$ & $4 \mathrm{~h}$ & Air \\
\hline $5 \mathrm{SS}$ & & & & & \multicolumn{3}{|c|}{ None } \\
\hline
\end{tabular}

Table 4. Symbols of steels.

\begin{tabular}{cccc}
\hline \multirow{2}{*}{ Cementite size } & \multicolumn{3}{c}{ Ferrite grain size } \\
\cline { 2 - 4 } & Large & Medium & Small \\
\hline Large & $10 \mathrm{LL}$ & - & $5 \mathrm{SL}$ \\
Medium & $10 \mathrm{LM}$ & $10 \mathrm{MM}$ & - \\
Small & $10 \mathrm{LS}$ & - & $10 \mathrm{SS} / 5 \mathrm{SS}$ \\
\hline
\end{tabular}

Table 2. Rolling conditions; (a) 10a, (b) $10 \mathrm{~b}$ and 5.

\begin{tabular}{|c|c|c|c|c|c|c|c|}
\hline \multicolumn{8}{|c|}{ (a) $10 \mathrm{a}$} \\
\hline \multirow{2}{*}{ Symbol } & \multicolumn{2}{|c|}{ Ingot forming } & \multirow{2}{*}{ Cooling } & \multicolumn{2}{|c|}{ Hot rolling } & \multirow{2}{*}{ Cooling } & \multirow{2}{*}{$\begin{array}{c}\text { Plate } \\
\text { thickness }\end{array}$} \\
\hline & Heating & Rolling & & Heating & Rolling & & \\
\hline $10 \mathrm{a}$ & $\begin{array}{c}1200^{\circ} \mathrm{CX} \\
1 \mathrm{~h}\end{array}$ & $\begin{array}{l}140 \mathrm{~mm} \times \\
140 \mathrm{~mm} \text { bar }\end{array}$ & Air & $\begin{array}{c}1200^{\circ} \mathrm{CX} \\
1 \mathrm{~h}\end{array}$ & Uncontrolled & Air & $25 \mathrm{~mm}$ \\
\hline
\end{tabular}

(b) $10 \mathrm{~b}$ and 5

\begin{tabular}{ccccccc}
\hline Symbol & Heating & $\begin{array}{c}\text { Rough rolling } \\
\text { start temp. }\end{array}$ & $\begin{array}{c}\text { Transfer } \\
\text { thickness }\end{array}$ & $\begin{array}{c}\text { Rolling finish } \\
\text { temp. }\end{array}$ & Cooling & Plate thickness \\
\hline $10 \mathrm{~b}$ & $\begin{array}{c}1200^{\circ} \mathrm{C} \\
\times 1 \mathrm{~h}\end{array}$ & $\begin{array}{c}1055^{\circ} \mathrm{C} \\
1065^{\circ} \mathrm{C}\end{array}$ & $40 \mathrm{~mm}$ & $\begin{array}{c}835^{\circ} \mathrm{C} \\
831^{\circ} \mathrm{C}\end{array}$ & $\begin{array}{c}\text { Controlled } \\
\text { water cooling }\end{array}$ & $25 \mathrm{~mm}$ \\
5 & & & 80 & \\
\hline
\end{tabular}




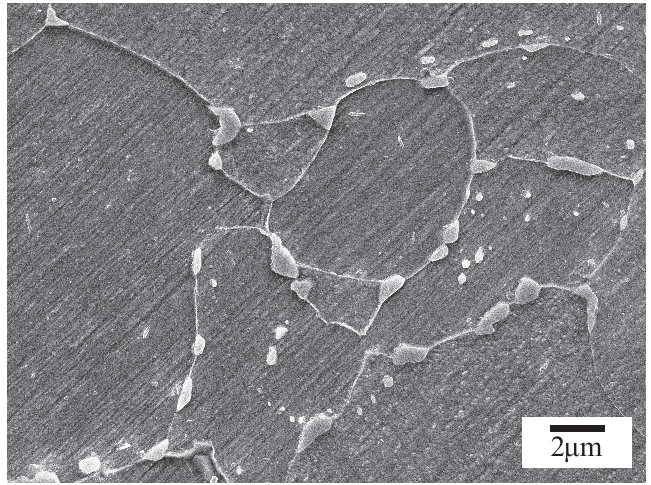

(a) SEM image

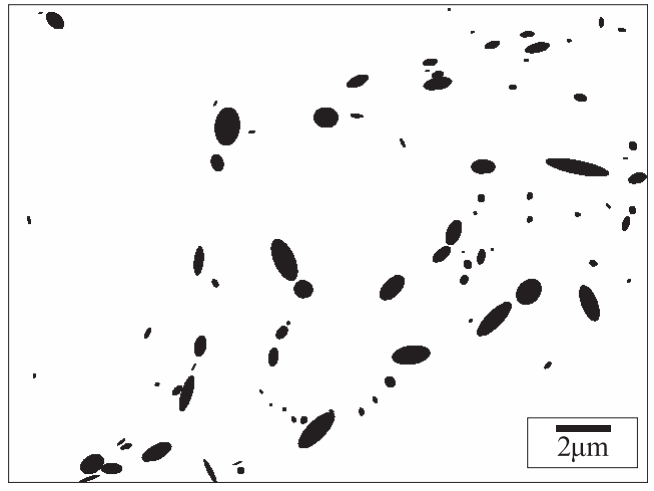

(b) Result of ellipse approximation

Fig. 1. Measurement of cementite particle size, 5SL.
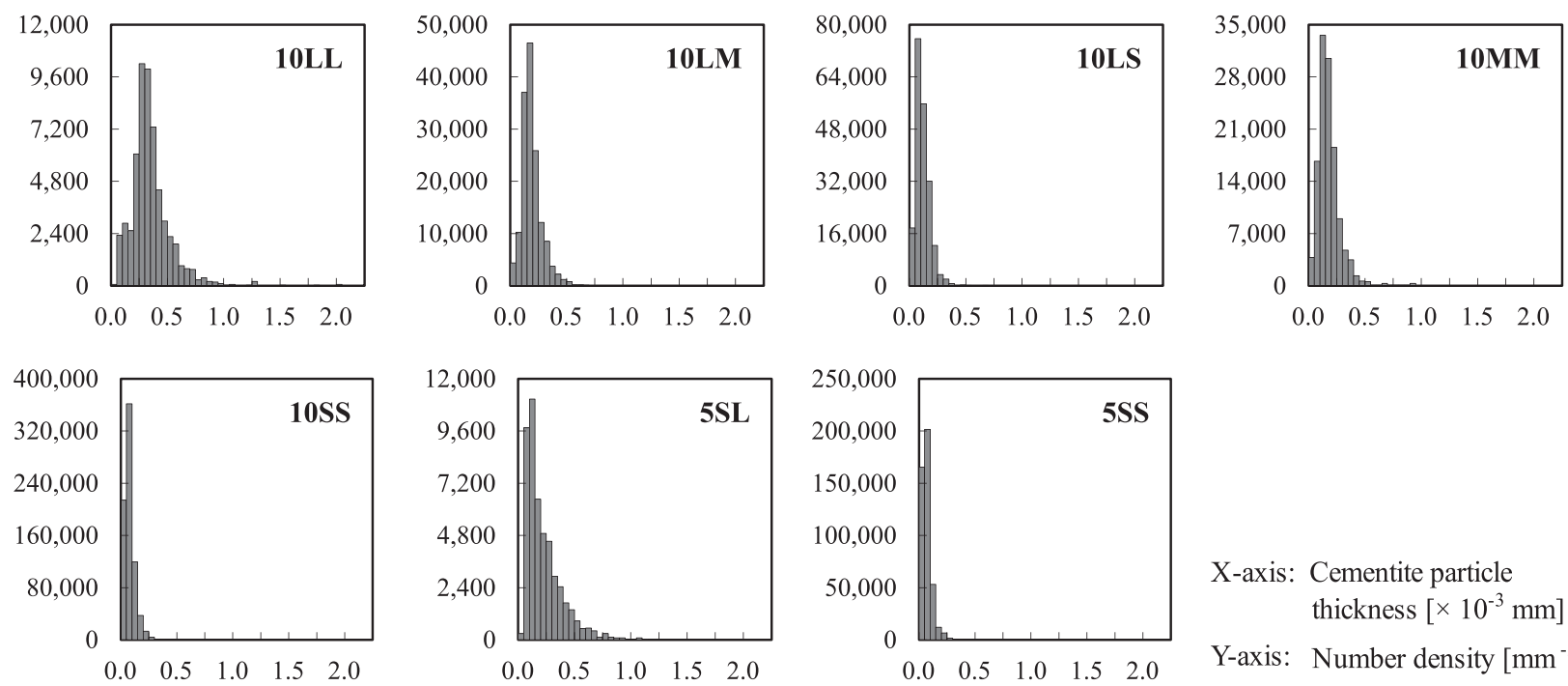

$\mathrm{X}$-axis: Cementite particle thickness $\left[\times 10^{-3} \mathrm{~mm}\right]$

Y-axis: Number density $\left[\mathrm{mm}^{-2}\right]$

Fig. 2. Distribution of cementite particle thickness.

Table 5. Representative values of cementite thickness, grain size and yield stress at room temperature.

\begin{tabular}{lcccccccc}
\hline \multicolumn{1}{c}{ Symbol } & 10LL & 10LM & 10LS & 10MM & 10SS & 5SL & 5SS \\
\hline Maximum cementite particle thickness $[\mu \mathrm{m}]$ & 2.02 & 1.10 & 0.66 & 0.93 & 0.49 & 1.15 & 0.44 \\
\hline Average aspect ratio of cementite particle & 2.29 & 2.89 & 4.99 & 4.55 & 3.02 & 3.45 & 3.31 \\
\hline \multirow{2}{*}{ Ferrite grain diameter $[\mu \mathrm{m}]$} & Average & 57 & 63 & 58 & 38 & 16 & 27 & 23 \\
\cline { 2 - 9 } & $\mathrm{Max}$ & 218 & 226 & 229 & 104 & 47 & 67 & 45 \\
\hline Yield stress at room temperature $[\mathrm{MPa}]$ & 161 & 170 & 171 & 215 & 247 & 213 & 248 \\
\hline
\end{tabular}




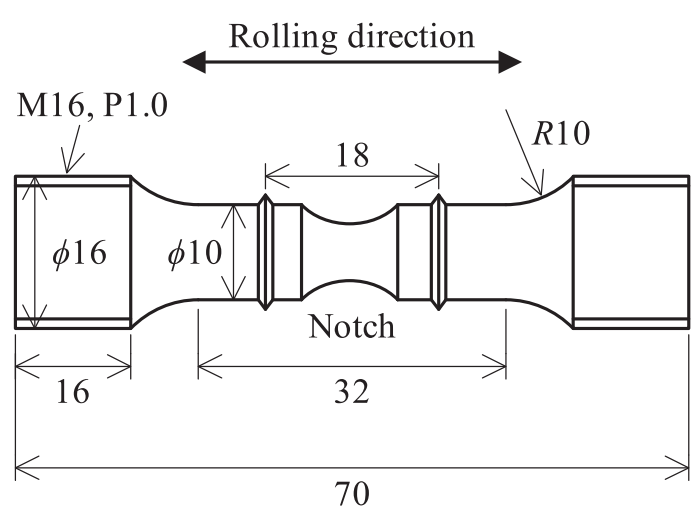

Detail of notch

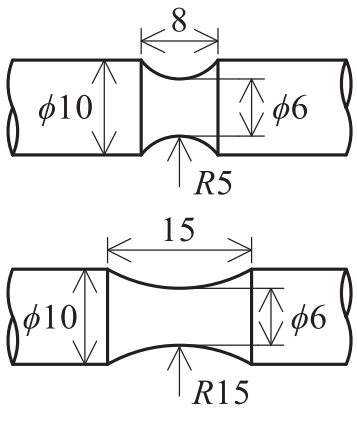

Unit: [mm]

Fig. 3. Configuration of circumferential notched round bar specimen.

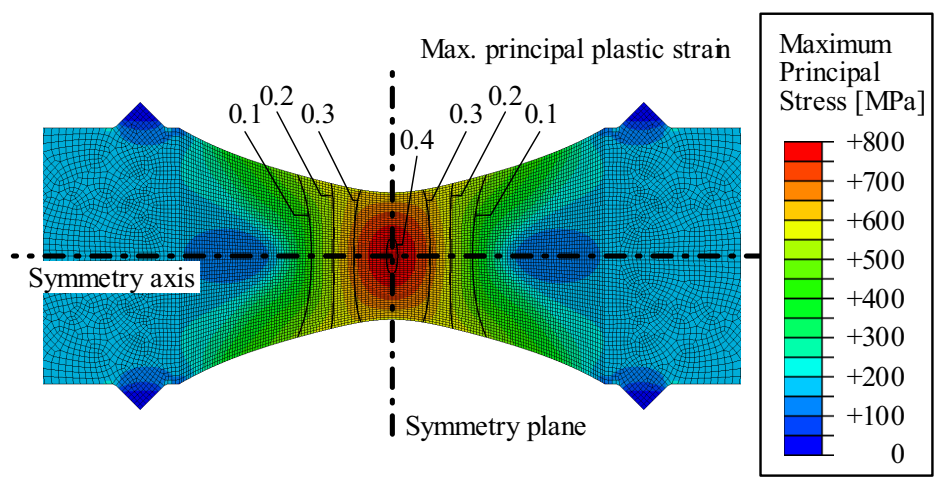

Fig. 4. Strain and stress distributions obtained by finite element analysis in the circumferential notched specimen, 10LM, $R=15 \mathrm{~mm},-80^{\circ} \mathrm{C}$. (Online version in color.)

obtained by a preliminary elasto-plastic finite element analysis. The finite element analysis was carried out using ABAQUS. ${ }^{17)}$ Large deformation and first order elements with full integration were employed.

As the boundary conditions, an axial symmetry is applied to the circumferential direction and a plane symmetry is applied to the axial direction. The number of elements was 2969. The minimal element size was $0.1 \mathrm{~mm}$ at the stress and strain concentration area. An example of the results of finite element analyses is shown in Fig. 4.

\subsection{Measurement of Cementite Cracking by SEM Observation}

The specimens were cut in the axis direction, and the sections were polished and etched by $2 \%$ nital. Lengths of crack in the cementite particles were measured by scanning the sections along the orthogonal direction of axis by a SEM observation. The applied maximum principal stress and equivalent plastic strain are assumed constant along the direction according to the results of finite element analysis as shown in Fig. 4. The applied stress and strain can be varied by changing the scanning location in the axial direction. The measurement was conducted under three or four conditions of applied stress and strain for respective steels and temperatures.

An example of the SEM images of the cracked cementite particles is shown in Fig. 5. An example of distributions of length of cementite crack is shown in Fig. 6. The respective relationships of the number of cracked cementite particles to the maximum principal stress and the equivalent plastic

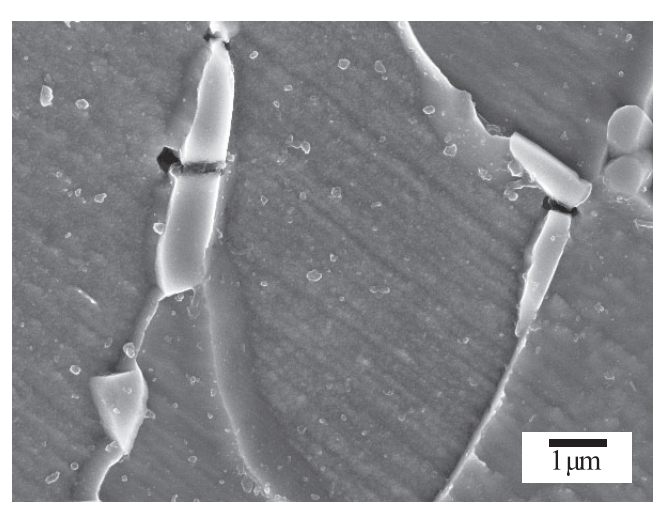

Fig. 5. SEM image of cracked cementite, 5SL, $\varepsilon_{p}=0.175$.

strain are shown in Fig. 7. The results clearly show that the higher applied stress and higher strain produces the larger number of cracked cementite particles. However, a more reasonable quantification must be required because the dependence of the applied stress and strain on the number of cracked cementite particles is largely different among the respective steels.

\subsection{Measurement on Crystal Orientation of Crack in Cementite}

A cleavage surface of a crystal is generally formed in a low Miller index plane. For example, it is well known that a cleavage plane of ferrite is $\{100\} .{ }^{18)}$ On the other hand, a cementite has an orthorhombic crystal structure whose unit cell has $12 \mathrm{Fe}$ atoms and $4 \mathrm{C}$ atoms as shown in Fig. 8. ${ }^{19-21)}$ 

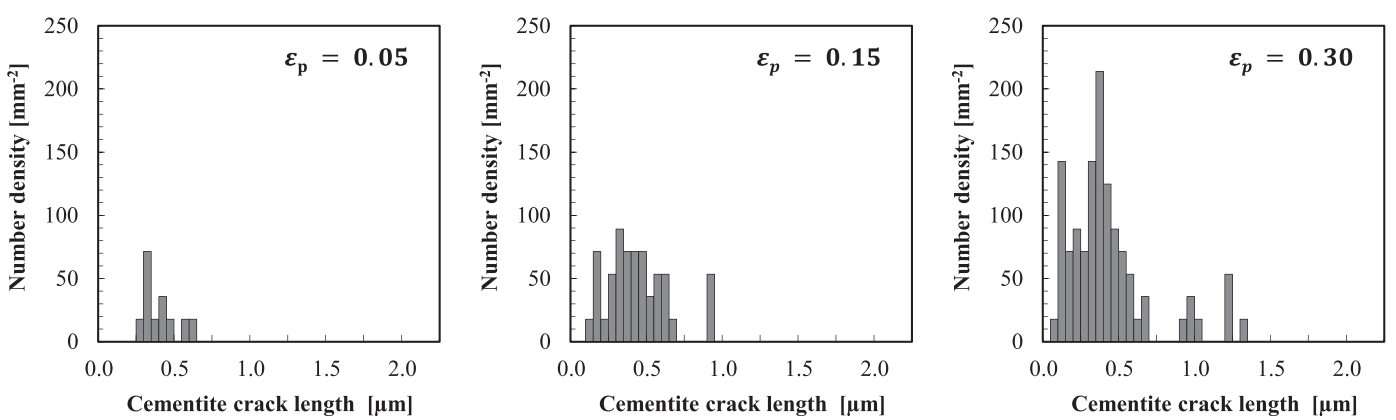

Fig. 6. Distribution of number of cracked cementite, $10 \mathrm{LL},-80^{\circ} \mathrm{C}$.

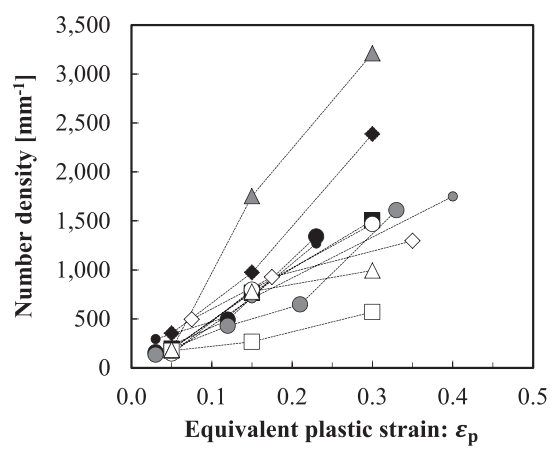

(a) Dependence on equivalent plastic strain

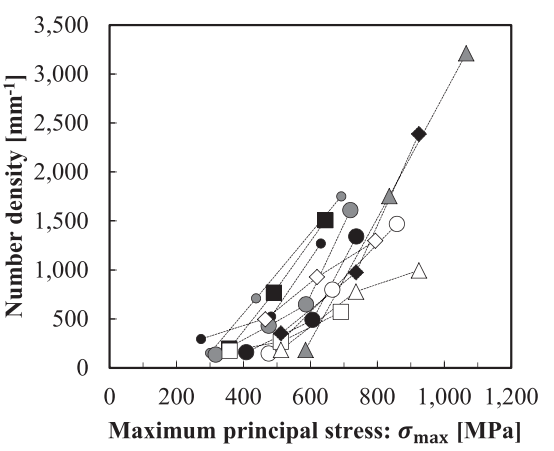

- $10 \mathrm{LL}, \mathrm{R} 15,-80^{\circ} \mathrm{C}$ -10LM, R5, $-40^{\circ} \mathrm{C}$ - $10 \mathrm{LM}, \mathrm{R} 15,-40^{\circ} \mathrm{C}$ -10LM, R5, $-80^{\circ} \mathrm{C}$ - $10 \mathrm{LM}, \mathrm{R} 15,-80^{\circ} \mathrm{C}$ $\circ 10 \mathrm{LM}, \mathrm{R} 15,-120^{\circ} \mathrm{C}$ $\square 10 \mathrm{LS}, \mathrm{R} 15,-80^{\circ} \mathrm{C}$ - 10MM, R15, $-100^{\circ} \mathrm{C}$ $\triangle 10 \mathrm{SS}, \mathrm{R} 15,-141^{\circ} \mathrm{C}$ $\diamond 5 \mathrm{SL}, \mathrm{R} 15,-104^{\circ} \mathrm{C}$ $\triangle 5 \mathrm{SS}, \mathrm{R} 15,-129^{\circ} \mathrm{C}$

(b) Dependence on maximum principal stress

Fig. 7. Number of cracked cementite.

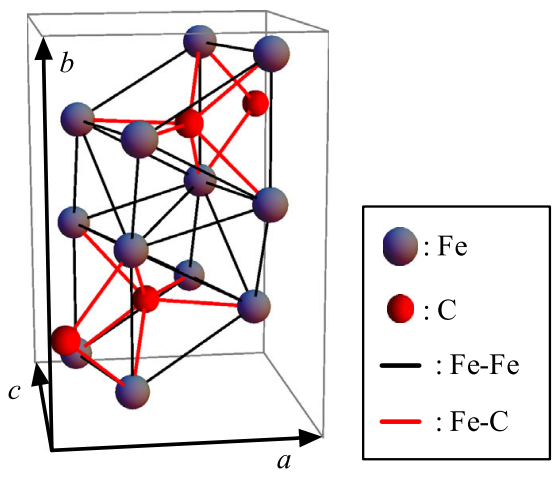

Fig. 8. Unit cell of cementite (Fe: 12, C: 4). (Online version in color.)

Its lattice constants are $a=5.058 \AA, b=6.703 \AA, c=4.506 \AA$, which slightly change depending on annealing temperature. However, the relationship between cleavage plane and crystal orientation in the cementite has not been clarified.

In this section, a measurement using the EBSD was conducted in order to clarify the crystal orientation of crack in the cementite.

For the specimen whose notch radius is $15 \mathrm{~mm}$ using the steel 10LL, which has the largest cementite particle size, the area of $\mathcal{E}_{\mathrm{p}}=15 \%$ was observed. After a carbon coating to ensure electrical conductivity, 13 cracks in 9 cementite particles were measured.

Some examples of the results are shown in Figs. 9(a) and 9(b). In these figures, the load is applied in the vertical direction. Although a Kikuchi-pattern of cementite is more difficult to be obtained than that of ferrite, it was found that all of the cementite particles measured in this study were single crystals. Local changes of crystal orientation in the ferrite near the cracks were also found. It is therefore expected to be caused by strain concentrations due to crack openings.

A trace analysis was carried out to investigate the relationship between cleavage surface and crystal orientation in the cementite particle. Considering the measurement error, it was assumed that the trace of crystal orientation matches a direction of a crack in the cementite particle if their difference is less than $\pm 10^{\circ}$.

Under the above condition, the comprehensive analyses considering symmetries of crystal planes were carried out by varying the range of Miller index from 0 to \pm 3 . However, there was no specific low Miller index plane matching with all of the 13 directions of the crack. This fact suggests that the cleavage plane in the cementite particle was not formed in only one specific crystal plane but in plural planes.

As mentioned above, the cementite is composed of $\mathrm{Fe}$ and $\mathrm{C}$ atoms. In the crystal structure, a (010) plane can be determined including only $\mathrm{Fe}-\mathrm{Fe}$ bond. The $\mathrm{Fe}-\mathrm{Fe}$ bond is a metallic bond. On the other hand, a $\mathrm{Fe}-\mathrm{C}$ bond has a property of a covalent bond. ${ }^{22)}$ Thus, the $\mathrm{Fe}-\mathrm{C}$ bond is about twice as strong as the Fe-Fe bond ${ }^{23)}$ and the slip deformation most easily takes place in the (010) plane. Due to the same reason, it is expected that the cleavage cracking also takes place most easily in the (010) plane.

According to the above consideration, the trace of (010) plane obtained by the EBSD and the direction of cleavage plane were compared. The results corresponding to Figs. 9(a) and 9(b) are shown in Fig. 9(c). Out of 13 cleavage planes, 10 planes matched the traces of (010) plane. This result strongly indicated that the cleavage cracking of cementite most easily formed in the (010) plane. However, there are some cracks which do not match the traces of (010) 

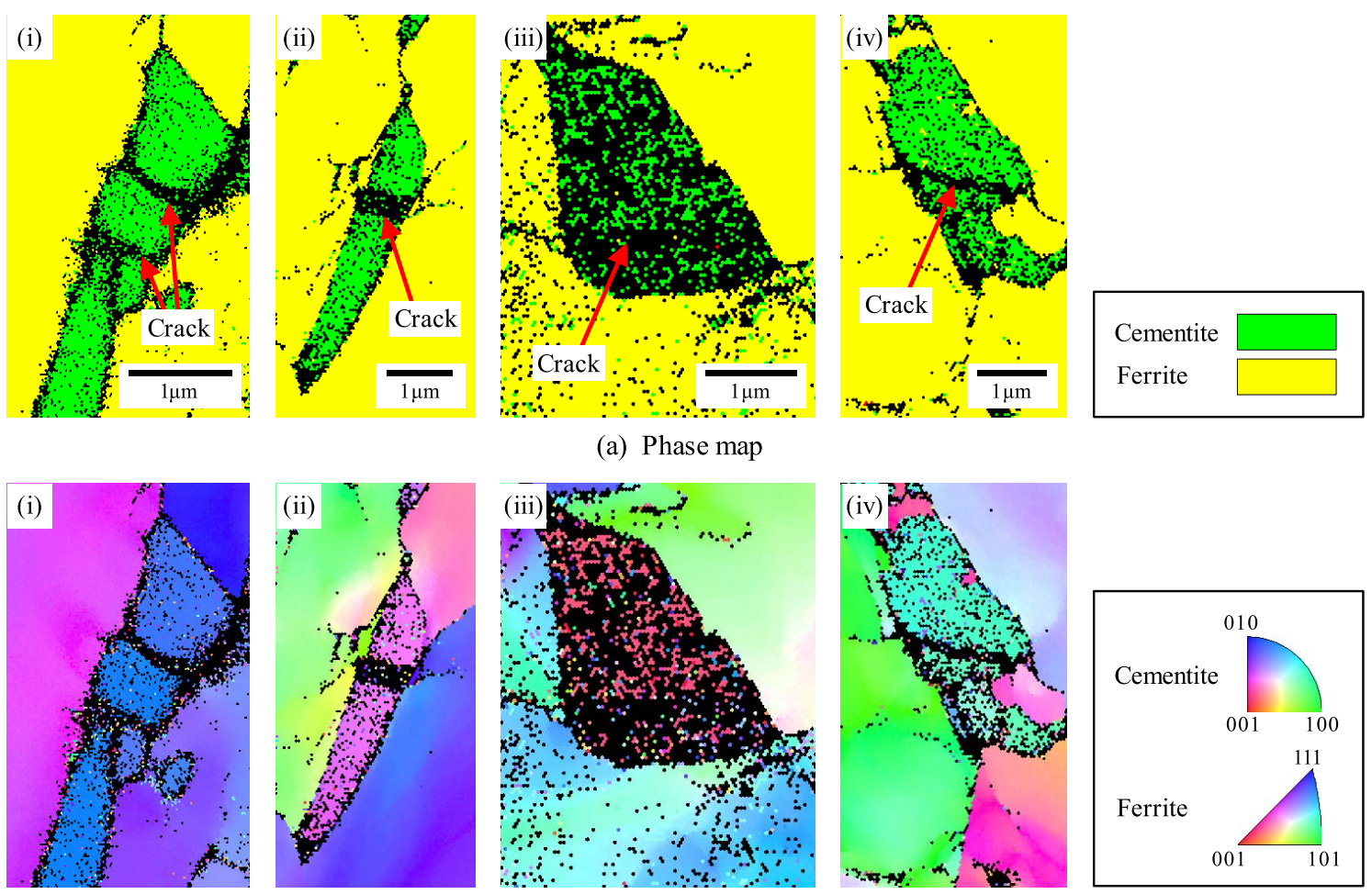

(a) Phase map
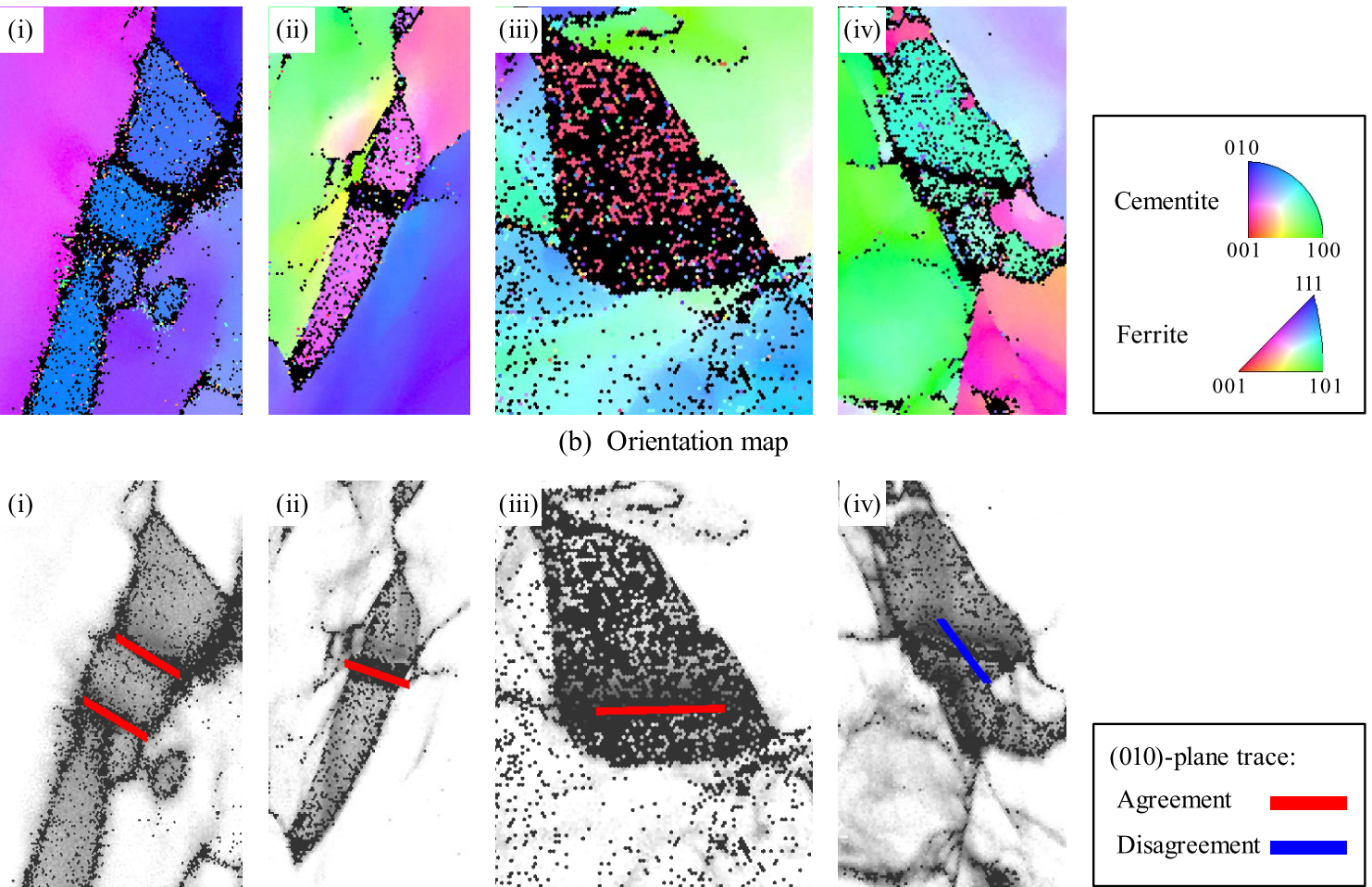

(b) Orientation map

(c) Comparison between (010)-plane trace and cleavage plane on image quality map

Fig. 9. EBSD maps of cementite particles and results of trace analysis to identify cleavage surface. (Online version in color.)

planes, as shown in Fig. 9 (iv). In these cases, the cracks may not be planar. A further detailed study is thus needed to clarify it.

\section{Estimation of Internal Stress of Cementite}

It is known that the cementite cracking depends on both macroscopically applied stress and strain. ${ }^{6,14)}$ On the other hand, in a microscopic aspect, the cementite cracking is expected to be generated when an internal stress of cementite particle reaches a critical value, i.e., fracture stress. In this section, a finite element analysis was first shown to clarify the microscopic behavior related to cementite cracking. An estimation formula of internal stress of a cementite particle in low carbon steels was then proposed based on the results of finite element analysis.

\subsection{Finite Element Model}

Assuming a flat cementite particle, which were mostly found in the previous observation, a two-phase finite element model was generated as a two-dimensional plane

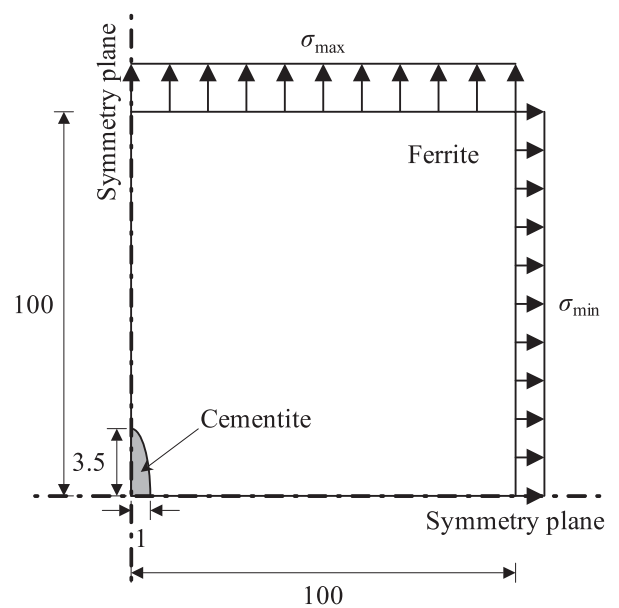

Fig. 10. Schematic of finite element model for microscopic ferritecementite steel.

strain problem. A schematic of the finite element model is shown in Fig. 10.

Young's modulus and Poisson's ratio of the ferrite phase 
were set as $E_{\alpha}=210 \mathrm{GPa}$ and $v_{\alpha}=0.3$, respectively. The yield stress $\sigma_{\mathrm{Y}}=500 \mathrm{MPa}$ was employed as a standard. A linear hardening stress-strain relationship with the slope of $2.1 \mathrm{GPa}\left(=E_{\alpha} / 100\right)$ was assumed after yielding. On the other hand, the cementite phase was modeled as an elastic body. Its Young's modulus and Poisson's ratio were $E_{\theta}=$ $189 \mathrm{GPa}$ and $v_{\theta}=0.26{ }^{24)}$

The shape of cementite particle was assumed as an ellipse. Although the longer shape of cementite particle in the loading direction makes the higher internal stress due to the fiber loading mechanism, ${ }^{6}$ the aspect ratio of particle was defined as 3.5 , which is the average obtained by the measurement in Section 2 (see Table 3).

The macroscopic maximum principal stress $\sigma$ max was assumed to be applied in the major axis direction of the cementite particle. Although this assumption would not always have generality, it satisfies the condition under the generated largest inner stress. In order to evaluate an influence of stress triaxiality, the ratio of the principal stresses $r_{\sigma}$ $\left(=\sigma_{\min } / \sigma_{\max }\right)$ was employed as a parameter.

Although a dispersive morphology of cementite particles would be an influencing factor on the inner stress of cementite particle in the actual ferrite-cementite steel, the influence is sufficiently small for a low carbon steel. Thus, it was assumed that there was a cementite particle inside of a sufficiently large ferrite matrix as a model. Although the length of model was not defined for generalization, the shape of entire model was defined as a square whose side length was defined one hundred times as long as the miner axis of cementite particle. In addition, a quarter-model was used considering the symmetry conditions. In the analysis, a large deformation was considered and first order full integrated elements were employed. A sufficiently detailed mesh was applied to the cementite particle and its surrounding ferrite matrix where stress and strain concentrations would be generated. The number of the element composed of the ferrite matrix was 3077 and that of the cementite particle was 393 .

In the following description, $\varepsilon_{\mathrm{p}}$ and $\sigma_{\theta}$ represent an equivalent plastic strain and an internal maximum principal stress of the cementite particle, respectively. The values of stress and strain are respectively normalized by the yield stress of ferrite matrix $\sigma_{\mathrm{Y}}$ and the yield strain $\varepsilon_{\mathrm{Y}}\left(=\sigma_{\mathrm{Y}} / E_{\alpha}\right)$ for generalization. The normalized values are represented with a bar $\left(^{-}\right)$.

\subsection{Estimation Formula}

A finite element analysis was conducted under the condition described in the previous Section 4.1. Figure 11 shows an example of the numerical results of maximum principal stress distribution near the cementite particle. It is found that the macroscopically higher applied stress produces the uniformly higher internal stress of the cementite particle.

Transitions of $\bar{\sigma}_{\theta}$ according to $\bar{\sigma}_{\max }$ and $\bar{\varepsilon}_{\mathrm{p}}$ under the various parameters of $\sigma_{\mathrm{Y}}$ and $r_{\sigma}$ are shown in Figs. 12 and 13. In these results, the maximum principal stress at the center of cementite particle is used as $\sigma_{\theta}$ for representative.

The results in Fig. 12 shows $\bar{\sigma}_{\theta}$ does not depend on $\sigma_{\mathrm{Y}}$.

On the other hand, the results in Fig. 13 shows the transition of $\bar{\sigma}_{\theta}$ depends on $r_{\sigma}$. It was found that $\bar{\sigma}_{\max }$ and $\bar{\sigma}_{\theta}$ have a linear relationship with the slope of the ratio of Young's modulus $r_{E}\left(=E_{\theta} / E_{\alpha}\right)$ until the yielding of ferrite matrix begins. Considering this fact, $\bar{\sigma}_{\theta}$ was separated by two components, as

$$
\sigma_{\theta}=\sigma_{\mathrm{e}}+\sigma_{\mathrm{p}}
$$

where $\bar{\sigma}_{\mathrm{e}}$ and $\bar{\sigma}_{\mathrm{p}}$ are components depending on the elastic

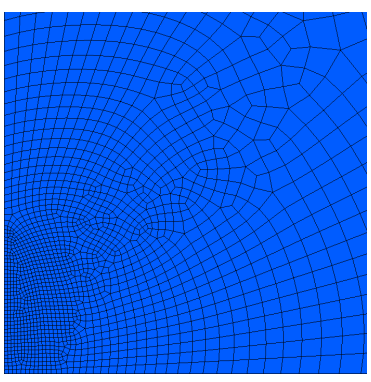

(a) $\bar{\sigma}_{\max }=1.0$

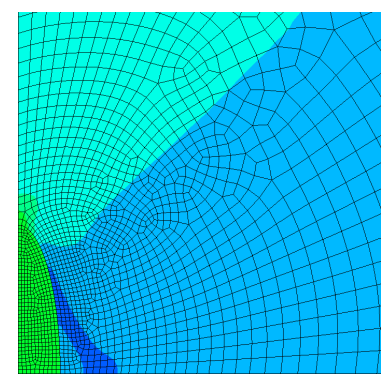

(b) $\bar{\sigma}_{\max }=1.5$

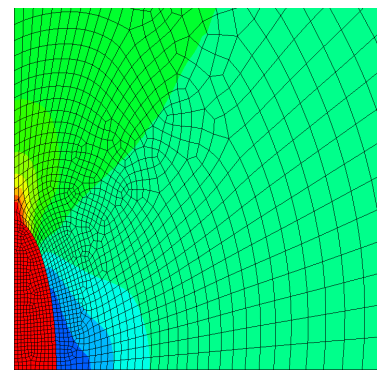

(c) $\bar{\sigma}_{\max }=2.5$

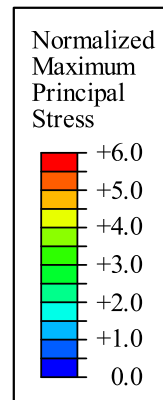

0.0

Fig. 11. Maximum principal stress in cementite particle and surrounding ferrite matrix, $\sigma_{\mathrm{Y}}=500 \mathrm{MPa}, r_{\sigma}=0.0$. (Online version in color.)

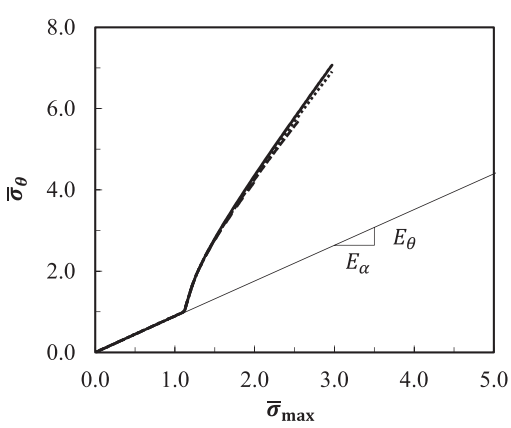

(a) Dependence on $\bar{\sigma}_{\max }$

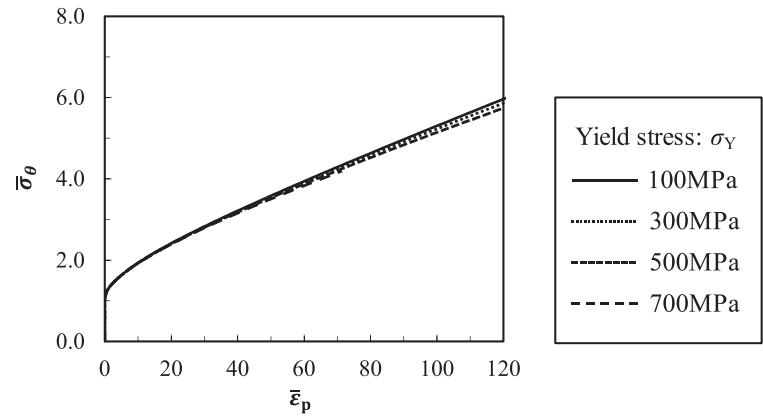

(b) Dependence on $\bar{\varepsilon}_{\mathrm{p}}$

Fig. 12. Internal maximum principal stress of cementite particle $\bar{\sigma}_{\theta}$ for various yield stress $\sigma_{\mathrm{Y}}, r_{\sigma}=0.0$. 


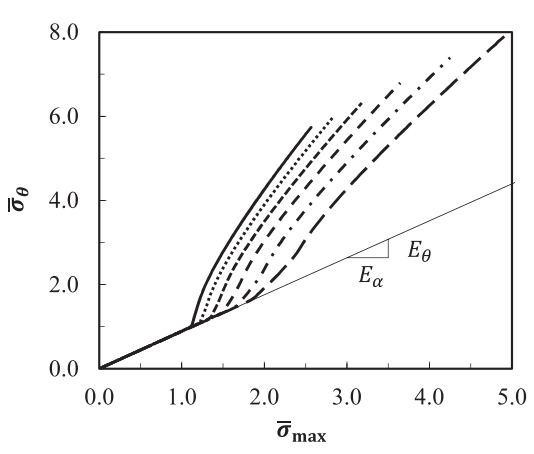

(a) Dependence on $\bar{\sigma}_{\max }$

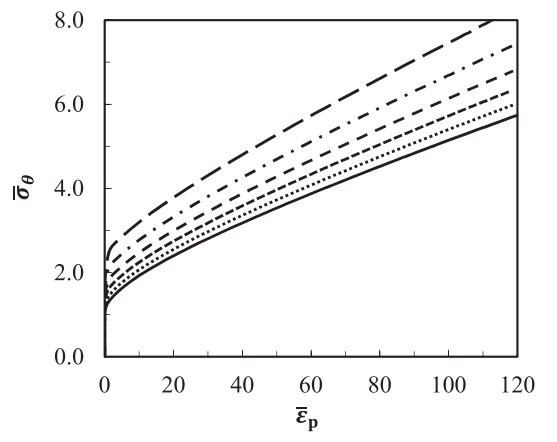

(b) Dependence on $\bar{\varepsilon}_{\mathrm{p}}$

Fig. 13. Internal maximum principal stress of cementite particle $\bar{\sigma}_{\theta}$ for various ratio of principal stress $r_{\sigma}, \sigma_{\mathrm{Y}}=500 \mathrm{MPa}$.

and plastic deformations, respectively. $\bar{\sigma}_{\mathrm{e}}$ can be expressed considering the relationship between $\bar{\sigma}_{\max }$ and $\bar{\sigma}_{\theta}$ up to the ferrite matrix yielding, as

$$
\sigma_{\mathrm{e}}=r_{E} \sigma_{\max }
$$

Then, $\bar{\sigma}_{\mathrm{p}}$, which is calculated as $\bar{\sigma}_{\theta}-\bar{\sigma}_{\mathrm{e}}$, depends on the plastic deformation of ferrite matrix. Thus, the dependence of $\bar{\sigma}_{\mathrm{p}}$ on $\varepsilon_{\mathrm{p}}$ was investigated. The relationship between $\bar{\sigma}_{\mathrm{p}}$ and $\varepsilon_{\mathrm{p}}$ is shown in Fig. 12. It was found that their relationship can be uniformly approximated irrespective of $r_{\sigma}$, as

$$
\bar{\sigma}_{\mathrm{p}}=0.179 \bar{\varepsilon}_{\mathrm{p}}^{0.627}
$$

The relationship described in Eq. (3) is shown as the red line in Fig. 14.

\section{Quantification of Cementite Cracking}

In Section 4, it was assumed that the shape of cementite particle is a flat ellipse and its internal stress was estimated as the function of macroscopic applied stress and strain. However, the cementite particles exist with various shapes in the microscopically inhomogeneous fields for actual steel. If their shapes can be approximated as flat ellipses, the internal stress is expected to depend on their aspect ratio and loading direction. Therefore, a probabilistic treatment is reasonable for the cementite cracking. In this section, the cementite cracking was quantified based on the measured distributions of cementite particle thickness and crack length.

\subsection{Dependence of Cementite Particle Thickness}

For the quantitative treatment of the distribution of cementite particle thickness $t$, the measured distributions were approximated using a function $g(t)$ considering the maximum thickness $t_{\max } g(t)$ is expressed as

$$
g(t)=C_{0}\left(1-\frac{t}{t_{\max }}\right) f(t)
$$

where $f(t)$ is a lognormal distribution function expressed as

$$
f(t)=\frac{\exp \left[-\frac{\{-\mu+\log t\}^{2}}{2 \sigma^{2}}\right]}{\sqrt{2 \pi} \sigma t}
$$

In the above Eqs. (4) and (5), $C_{0}, \sigma$ and $\mu$ are fitting parameters. $t_{\max }$ was assumed as 1.05 times the maximum measured thickness as shown in Fig. 2 and Table 3. Figure 15

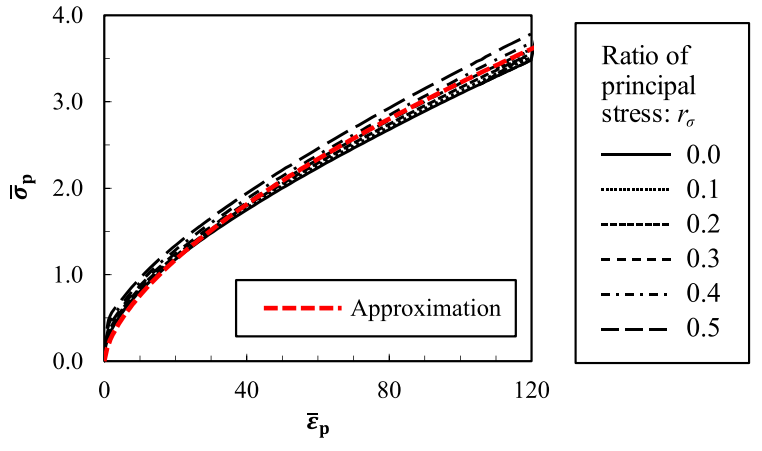

Fig. 14. Relationship between $\varepsilon_{\mathrm{p}}$ and $\sigma_{\mathrm{p}}, \sigma_{\mathrm{Y}}=500 \mathrm{MPa}$. (Online version in color.)

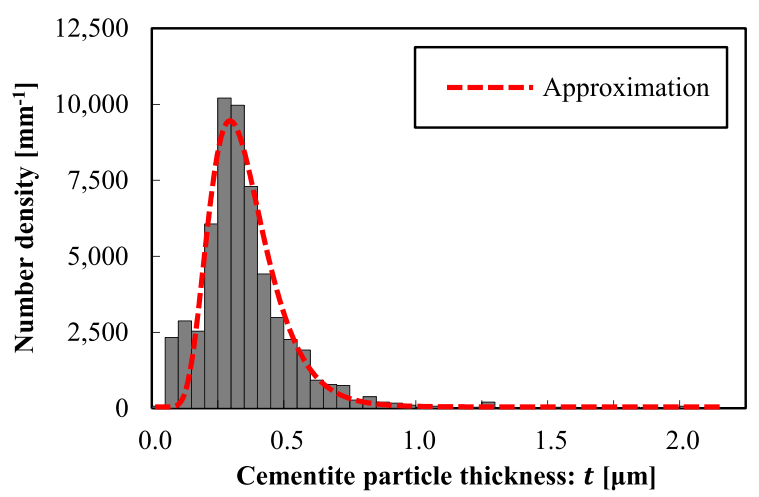

Fig. 15. Approximation of cementite particle thickness distribution, 10LL. (Online version in color.)

shows an example of the approximation of the distribution of cementite particle thickness using $g(t)$.

The distributions of crack length were then quantified. The crack length in the cementite particle was assumed to be equivalent to its thickness because the crack generally occurred in its thickness direction. It was reported that the thicker cementite particle is more likely to crack in the past experimental investigations. ${ }^{14)}$ According to the facts, a probability of cementite cracking $r_{\mathrm{c}}$ was assumed to be proportional to a power of $t$, expressed as

$$
r_{c}=C t^{m}
$$

Considering the above definition of $r_{\mathrm{c}}$, the measured distributions of crack length was approximated using a distribution function $h(t)$, which is defined as

$$
h(t)=C t^{m} g(t)
$$



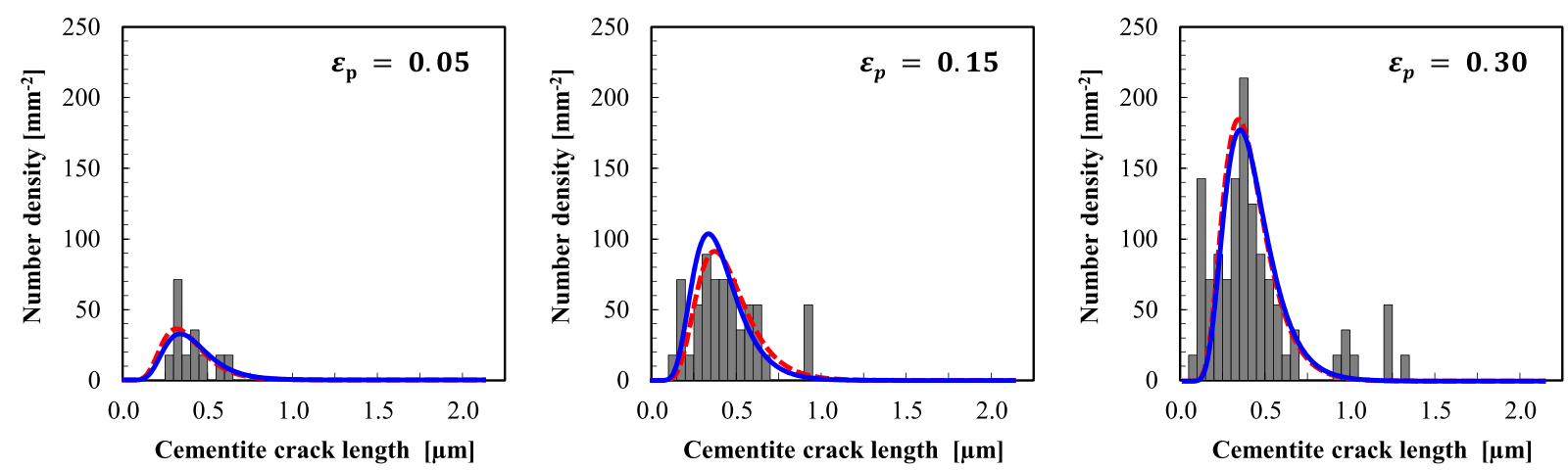

Fig. 16. Approximation of cementite crack length distribution, $10 \mathrm{LL}, \mathrm{R} 15,-80^{\circ} \mathrm{C}$ (Dashed line: fitting two parameters $C$ and $m$, Solid line: fitting only $C$ and $m=2.47)$. (Online version in color.)

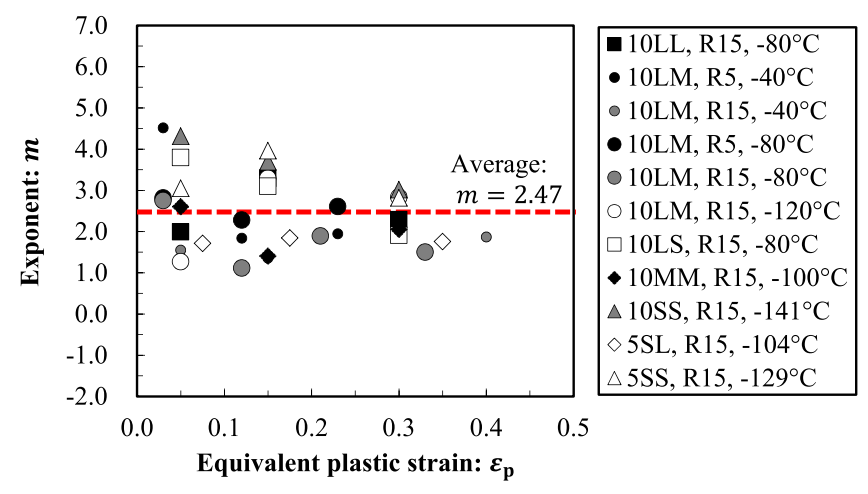

Fig. 17. Exponent $m$ in distribution function $h(t)$. (Online version in color.)

where $C$ and $m$ are used as fitting parameters. In particular, $C$ has a physical meaning of a probability of cracking in the cementite particle of unit thickness.

An example of the approximation of the distribution of crack length in the cementite particle using $h(t)$ is shown in Fig. 16. The obtained values of $m$ corresponding to the equivalent plastic strain $\mathcal{E}_{\mathrm{p}}$ for the respective conditions are shown in Fig. 17. Although a large scatter was found in the case of low $\varepsilon_{\mathrm{p}}$ possibly due to insufficient number of data, the average of $m$ was 2.47 .

\subsection{Dependence of Applied Stress and Strain}

As mentioned in Section 4, a cementite cracking is expected to be generated when an internal stress of cementite particle reaches a certain fracture stress. It was thus assumed that the parameter $C$, whose meaning is a probability of cracking in the cementite particle of unit thickness, is a function of the internal stress of cementite particle.

Now, $m$ has been fixed as 2.47 considering the results of Section 5.1. Under this condition, the measured distributions of crack length are approximated using $h(t)$ again with $C$ as only one fitting parameter, as shown in the blue lines in Fig. 16 . By the way, $\sigma_{\theta}$ can be estimated using the macroscopic maximum principal stress and equivalent plastic strain obtained by the finite element analyses. A relationship between the obtained values of $C$ and $\sigma_{\theta}$ is plotted in Fig. 18. For the determination of the value of $C$, the unit of $\mu \mathrm{m}$ was used for cementite particle thickness. According to the results, the relationship between $C$ and $\sigma_{\theta}$ was approximated as

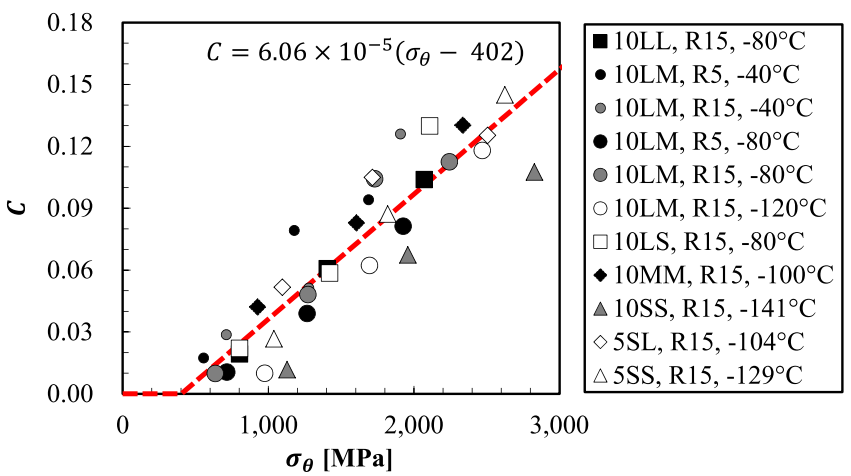

Fig. 18. Relationship between $C$ and $\sigma_{\theta}$. (Online version in color.)

$$
C=6.06 \times 10^{-5}\left(\sigma_{\theta}-402\right)
$$

\subsection{Estimation Formula of Ratio of Cementite Crack- ing}

As mentioned above, the cementite particles exist with various shapes in the microscopically inhomogeneous fields for actual steel. A probabilistic treatment is reasonable for the cementite cracking.

Summarizing the quantification of cementite cracking in the present study, the probability of cementite cracking $r_{\mathrm{c}}$ was quantified as a function of three variables, which are the macroscopic maximum principal stress $\sigma_{\max }$, equivalent plastic strain $\mathcal{E}_{\mathrm{p}}$ and cementite thickness $t$. The formulation is defined by the combination of Eqs. (1)-(3), (6) and (8), as

$$
r_{c}=6.06 \times 10^{-5}\left\{r_{E} \sigma_{\max }+0.179 \sigma_{\mathrm{Y}}\left(\frac{\varepsilon_{\mathrm{p}}}{\varepsilon_{\mathrm{Y}}}\right)^{0.627}-402\right\} t^{2.47} \ldots
$$

where $\sigma_{\mathrm{Y}}$ and $\varepsilon_{\mathrm{Y}}$ are the yield stress and strain, respectively. $r_{E}$ is the ratio of Young's modulus of cementite and ferrite $\left(=E_{\theta} / E_{\alpha}\right)$. It is noted that this equation was formulated for low carbon steels. Thus, an further investigation is required for medium or high carbon steels because the ratio of cementite cracking would be influenced by an interaction among cementite particles.

\section{Conclusions}

In the present study, the observation and reasonable quantification of cementite cracking in the ferrite-cementite steels was carried out, and the followings are concluded. 
The distributions of cementite particle thickness in the steels with various sizes of microstructures produced by the combination of laboratory vacuum melting and rolling were measured by the SEM observation and image analysis.

The tensile tests using circumferential notched round bar specimens were conducted based on the preliminary finite element analysis. The distributions of length of cracks generated in the cementite particles were measured for various strain and stress conditions of the respective steels.

The EBSD analysis was conducted for cracked cementite particles. As the results of the comparison between direction of cracks and traces of crystal planes, it was shown that most of the cleavage surfaces in the cementite particles are formed on (010) plane. However, the detailed investigation would be needed.

In order to understand the microscopic mechanism of cementite cracking, the finite element analysis was carried out. The shape of cementite particle was assumed as an ellipse. The estimation formula of internal stress of the cementite particle by using macroscopic stress and strain was developed based on the numerical results.

A nucleation of cementite cracking is reasonably quantitated based on a stochastic framework because the cementite particles exist with various shapes in the microscopically inhomogeneous fields. Thus, the measured distributions of cementite particle thickness and crack length were approximated by introducing a distribution function considering the maximum value. The probability of nucleation of cementite cracking was quantified as a function of cementite particle thickness and macroscopic stress and strain, based on the approximated distribution function and the estimation formula of internal stress of cementite particle.

\section{Acknowledgements}

The test steels were prepared by Dr. Tsunehisa Handa of JFE Steel Corporation and Mr. Hiroyuki Shirahata of Nippon Steel \& Sumitomo Metal Corporation in a part of research project of The Iron and Steel Institute of Japan (ISIJ). A part of this work was supported by "Nanotechnology Platform" (project No. 12024046) of the Ministry of Education, Culture, Sports, Science and Technology (MEXT), Japan. The authors would like to thank them.

\section{REFERENCES}

1) W. C. Leslie: The Physical Metallurgy of Steels, trans. by N. Koda, H. Kumai, T. Noda, Maruzen, Tokyo, (1985), (in Japanese).

2) D. A. Curry and J. F. Knott: Met. Sci., 12 (1978), 511.

3) E. A. Almond, D. H. Timbres and J. D. Embury: Proc. of 2nd Int. Conf. on Fracture, Chapman \& Hall, London, (1969), 253.

4) N. J. Petch: Acta Metall., 34 (1986), 1387.

5) L. E. Kaeghele and A. S. Tetelman: Acta Metall., 17 (1969), 463.

6) T. C. Lindley, G. Oates and C. E. Richards: Acta Metall., 18 (1970), 1127.

7) J. Gurland: Acta Metall., 20 (1972), 735

8) F. M. Beremin: Metall. Mater. Trans. A, 14 (1983), 2277.

9) ASTM E1921, Standard test method for determination of reference temperature, to, for ferritic steels in the transition range, ASTM, Pennsylvania, USA, (2013).

10) ISO 27306, Metallic materials - Method of constraint loss correction of CTOD fracture toughness for fracture assessment of steel components, ISO, Genève, Switzerland, (2009).

11) H. Mimura: J. High Press. Inst. Jpn., 39 (2001), 281.

12) S. R. Bordet, A. D. Karstensen, D. M. Knowles and C. S. Wiesner: Eng. Fract. Mech., 72 (2005), 435.

13) S. R. Bordet, A. D. Karstensen, D. M. Knowles and C. S. Wiesner: Eng. Fract. Mech., 72 (2005), 453.

14) K. Shibanuma, S. Aihara, M. Matsubara, H. Shirahata and T. Handa: Tetsu-to-Hagané, 99 (2013), 40.

15) W. S. Rasband: ImageJ, U. S. National Institutes of Health, Bethesda, Maryland, USA, (1997-2011), http://rsb.info.nih.gov/ij/, (accessed 2014-5-23).

16) TSL Solutions, OIM Analysis, ver.6.1, TSL Solutions, Kanagawa, Japan, (2011).

17) SIMULIA, Abaqus Analysis User's Manual, Version 6.10, Dassault Systemes, Vélizy-Villacoublay, France, (2011).

18) A. S. Tetelman and A. J. McEvily, Jr.: Fracture of Structural Materials, Vol. 1, trans. by H. Miyamoto, Baihukan, Tokyo, Japan, (1970), (in Japanese).

19) Handbook of Iron and Steel, 1st ed., ISIJ, Tokyo, (1981), 438 (in Japanese).

$20)$ I. R. Shein, N. I. Medvedeva and A. L. Ivanovskii: Physica B, 371 (2006), 126.

21) W. C. Chiou, Jr. and E. A. Carter: Surf. Sci., 530 (2003), 87.

22) M. Umemoto: Tetsu-to-Hagané, 88 (2002), 117.

23) A. H. Cottrell: Mater. Sci. Technol., 9 (1993), 277.

24) M. Umemoto: Bull. Iron Steel Inst. Jpn., 9 (2004), 151. 